\title{
вMJ Global Health Operationalisation of consensual One Health roadmaps in countries for improved IHR capacities and health security
}

Stephane de la Rocque, ${ }^{1}$ Guillaume Belot, ${ }^{1}$ Kaylee Marie Myhre Errecaborde, ${ }^{1,2}$ Rajesh Sreedharan, ${ }^{1}$ Artem Skrypnyk, ${ }^{3}$ Tanja Schmidt, ${ }^{3}$ Nicolas Isla, ${ }^{3}$ Tieble Traore, ${ }^{4}$ Ambrose Talisuna (D) , ${ }^{4}$ Gyanendra Gongal, ${ }^{5}$ Dalia Samhouri, ${ }^{6}$ François Caya, ${ }^{7}$ Maud Carron, ${ }^{7}$ Nirmal Kandel, ${ }^{1}$ Jun Xing, ${ }^{1}$ Stella Chungong ${ }^{1}$

To cite: de la Rocque S, Belot G, Errecaborde KMM, et al. Operationalisation of consensua One Health roadmaps in countries for improved IHR capacities and health security. BMJ Global Health 2021;6:e005275. doi:10.1136/ bmjgh-2021-005275

Handling editor Seye Abimbola

Received 5 February 2021

Revised 22 April 2021

Accepted 24 April 2021
Check for updates

(c) World Health Organization 2021. Licensee BMJ.

For numbered affiliations see end of article.

Correspondence to Dr Stephane de la Rocque; delarocques@who.int

\section{ABSTRACT}

The COVID-19 pandemic is a devastating reminder that mitigating the threat of emerging zoonotic outbreaks relies on our collective capacity to work across human health, animal health and environment sectors. Despite the critical need for shared approaches, collaborative benchmarks in the International Health Regulations (IHR) Monitoring and Evaluation Framework and more specifically the Joint External Evaluation (JEE) often reveal low levels of performance in collaborative technical areas (TAs), thus identifying a real need to work on the human-animalenvironment interface to improve health security. The National Bridging Workshops (NBWs) proposed jointly by the World Organisation of Animal Health and World Health Organization (WHO) provide opportunity for national human health, animal health, environment and other relevant sectors in countries to explore the efficiency and gaps in their coordination for the management of zoonotic diseases. The results, gathered in a prioritised roadmap, support the operationalisation of the recommendations made during JEE for TAs where a multisectoral One Health approach is beneficial. For those collaborative TAs (12 out of 19 in the JEE), more than two-thirds of the recommendations can be implemented through one or multiple activities jointly agreed during NBW. Interestingly, when associated with the WHO Benchmark Tool for IHR, it appears that NBW activities are often associated with lower level of performance than anticipated during the JEE missions, revealing that countries often overestimate their capacities at the human-animal-environment interface. Deeper, more focused and more widely shared discussions between professionals highlight the need for concrete foundations of multisectoral coordination to meet goals for One Health and improved global health security through IHR.

\section{INTRODUCTION}

While the world is actively fighting against COVID-19, we must acknowledge that in the past two decades, experts have predicted increased frequency of animal-human

SUMMARY BOX
$\Rightarrow$ The COVID-19 pandemic is a devastating reminder
that mitigating the threat of emerging zoonotic out-
breaks relies on our collective effort and capacity to
work across human health, animal health and envi-
ronment sectors.
$\Rightarrow$ Coordination between human health, animal health
and environment sectors in countries can be im-
proved when the International Health Regulations
(IHR) and World Organisation of Animal Health's
Performance of Veterinary Services (PVS) frame-
works are viewed in tandem, as accomplished
through the IHR-PVS National Bridging Workshops
(NBWs).
$\Rightarrow$ An analysis of NBW activities and collaborative in-
dicators reported by countries in the Joint External
Evaluation reveals that countries tend to overesti-
mate their capacities at the human-animal-envi-
ronment interface.
$\Rightarrow$ A deeper, more nuanced discussion between profes-
sionals highlights the need for concrete foundations
of multisectoral coordination in international frame-
works for evaluation, ultimately supporting improved
global health security through the implementation of
the IHR.

contacts and the likelihood of emergence of zoonotic pathogens, suggesting that 'pandemics will become more frequent and more devastating in the future (and) face all countries because once diseases emerge, they travel rapidly and freely through our global networks of travel and trade'. ${ }^{1}$ Controlling potential emerging pathogens in animals is challenging, if not unrealistic, in particular in wildlife populations. ${ }^{2}$ Limiting the impact of such emergences relies on the capacity of countries to rapidly detect and respond to outbreaks as soon as they become apparent in animals, in humans or both. Therefore, an 
efficient early warning and response system for zoonotic events requires routine collaboration between human health services, animal health services and environment services to cover both domestic and wild animals, possibly further informed by the monitoring of environmental factors known to drive emergence or amplification of zoonotic diseases. ${ }^{3}$ When used to support operational coordination, a multisectoral or One Health approach to collaboration allows for improved performance in surveillance, real-time sharing of information, joint risk assessment, field investigation and riposte across sectors and between multiple actors. ${ }^{45}$

The tripartite (Food and Agriculture Organization (FAO), World Organisation of Animal Health (OIE) and WHO) defines One Health as 'an approach to address a health threat at the human-animal-environment interface based on collaboration, communication, and coordination across all relevant sectors and disciplines, with the ultimate goal of achieving optimal health outcomes for both people and animals'. ${ }^{5}$ In this definition, a One Health approach is applicable at the subnational, national, regional and global levels. Benefits of sharing information, joint planning and coordinating actions between human health, animal health and environment sectors have been documented in several papers including by Zinsstag et $a l^{6}{ }^{6}$ with concrete examples of the advantage of One Health for the prevention and control of zoonotic diseases provided. ${ }^{6}$ However, the author recognises that 'communication on zoonoses is often totally lacking between public-health and veterinary authorities (and) interactions should be better institutionalised and responsibilities clarified' (p2143). The need for institutionalisation and clarification of respective roles and mandates in the management of zoonotic events had been critically experienced and successfully overcome during the H5N1 highly pathogenic avian influenza crisis. While the epidemic was instrumental in catalysing multisectoral action, the attention was often difficult to maintain once the crisis was over and other priorities asserted demands and resources. ${ }^{7}$ It is precisely in "peace time' that joint mechanisms and collaborations between sectors should be organised to improve preparedness for similar challenges to come. Maintaining the momentum on One Health is a daunting task and needs a driving force enabling the institutionalisation of the approach, national ownership and the political support to implement it at national and international levels. ${ }^{89}$

\section{THE INTERNATIONAL HEALTH REGULATION (2005) AS A DRIVING FORCE}

Large-scale transboundary infectious events of zoonotic nature, including the $2009 \mathrm{H} 1 \mathrm{~N} 1$ influenza pandemic, the Ebola outbreak in West Africa in 2014-2016 and more recently the COVID-19 pandemic, brought renewed attention to the multidimension of such events, the imperious necessity to engage multiple sectors in the response, the risk posed to global health security by a country's deficient detection and response capacities and the urgent need to increase preparedness and readiness, and to ensure comprehensive and immediate interventions. This highlights the importance of complying with the International Health Regulations (IHR). ${ }^{10}$

The IHR was adopted by all WHO member states in 1969 and was initially focusing on a limited number of diseases with the potential to disseminate internationally. In consideration of the increase in international travel and trade, and the emergence, re-emergence and international dissemination of diseases and other health threats, the World Health Assembly (WHA) called for a significant revision in 2005 with the objectives to 'prevent, protect against, control and provide a public health response to the international spread of disease in ways that are commensurate with and restricted to public health risks, and which avoid unnecessary interference with international traffic and trade'.

As a legally binding framework, the IHR provides rights and obligations to both WHO and state parties (all WHO members and few other countries). In particular, state parties have committed to have or develop minimum core public health capacities to implement the IHR (2005) effectively and to report their level of compliance to the WHA on a yearly basis. This commitment is transposed at their behest into their legislative and regulatory framework, for implementation as appropriate in their specific context. Because the IHR (2005) is a commitment at the highest levels of the governments, is not restricted to the public health sector and encourages a whole-ofgovernment response to health risks, it can be used as a driving force to encourage the previously mentioned institutionalisation of interactions between sectors and constitutes a privileged platform to operationalise the One Health approach towards the prevention, detection and control of public health events. ${ }^{11}$

The opportunity to use the supportive framework and legally binding environment offered by the regulations to support collaborative efforts at the human-animal-environment interface was initially challenged by the limited knowledge about the IHR (2005) in sectors other than human health. ${ }^{12}$ The contribution of the veterinary sector in each of the core capacities included in the IHR (2005) was explored, including their links with international standards for animal health, such as the OIE Aquatic and Terrestrial Animal Health Codes. ${ }^{13}$ With respect to respective mandates and prerogatives, efforts were made to highlight complementarities and to inform the veterinary sector about the IHR (2005) and the relevance of its involvement to increase the visibility and consideration of its deliveries. Similar efforts crossing from the animal health sector to the public health sector have allowed for an improved understanding of the missions and activities of the veterinary services and possible synergies for improved performance.

More concrete connections were possible when the OIE's Performance of Veterinary Services (PVS) pathway was confronted to the IHR assessment tools and PVS 
indicators (called critical competencies) linked to IHR core capacities. ${ }^{13}$ The PVS pathway is the framework for assessing compliance of the veterinary services with internationally adopted standards and for providing support for improvement. ${ }^{14}$ The bridging between the two frameworks was explored and put into practice rapidly after international communities called for more concrete actions to improve compliance with the IHR (2005), particularly regarding capacities at the humananimal-environment interface. Using legal and regulatory frameworks as foundation was a deliberate decision, since national professionals are familiar with and have experience with working under the IHR (2005) and the OIE frameworks in the public health and animal health sectors, respectively. This knowledge was an asset to ensure both sectors take ownership of results of the bridging exercise and make the necessary adjustments at the human-animal-environment interface.

\section{LINKING EVALUATION FRAMEWORKS ACROSS HUMAN AND ANIMAL HEALTH SECTORS}

After the West African Ebola outbreak in 2014, the IHR Review Committee recommended WHO to develop the
IHR Monitoring and Evaluation Framework (MEF) to support countries in monitoring and enhancing their capacities and complying with the IHR (2005). ${ }^{15}$ This framework comprises various components, including the State Party Annual Report (SPAR), which facilitate the mandatory annual reporting of countries of their level of compliance with IHR (2005) and the Joint External Evaluation (JEE) tool, which is a voluntary review of IHR core capacities conducted jointly by national and external experts. ${ }^{16}$ The contribution of the veterinary sector in each of these components has been summarised elsewhere. ${ }^{11}$ In 2017, WHO and OIE published a handbook aiming to facilitate the review of JEE technical areas (TAs) by highlighting the role of the Veterinary Services in 16 of the 19 JEE TAs (see table 1) and, out of these TAs, identifying synergies between 35 JEE indicators and the PVS critical competencies. ${ }^{17}$ These obviously include TAs focusing more specifically on (1) zoonotic diseases, (2) food safety and (3) antimicrobial resistance, but also other TAs such as surveillance, laboratory and response for which multisectoral aspects are usually more neglected in the discussion. ${ }^{18}$ This effort to improve collaboration during the JEE missions, including through more veterinarians and

Table 1 Association between recommendations made during the JEE missions and joint activities identified during NBW

\begin{tabular}{|c|c|c|}
\hline $\begin{array}{l}\text { (A) JEE TAs with a possible or needed } \\
\text { contribution of the animal health sector }\end{array}$ & $\begin{array}{l}\text { (B) JEE TAs with a link between } \\
\text { JEE recommendations and NBW } \\
\text { activities }\end{array}$ & $\begin{array}{l}\text { (C) Proportion (and \%) of JEE } \\
\text { recommendations to which NBW } \\
\text { activities are associated }\end{array}$ \\
\hline National legislation, policy and financing & $\begin{array}{l}\text { National legislation, policy and } \\
\text { financing (4) }\end{array}$ & $3 / 6(50 \%)$ \\
\hline IHR coordination, communication and advocacy ${ }^{\star}$ & $\begin{array}{l}\text { IHR coordination, communication } \\
\text { and advocacy (15) }\end{array}$ & $7 / 9(78 \%)$ \\
\hline Antimicrobial resistance & - & \\
\hline Zoonotic diseases* & Zoonotic diseases (15) & $9 / 10(90 \%)$ \\
\hline Food safety & Food safety (15) & $6 / 12(50 \%)$ \\
\hline Biosafety and biosecurity & - & \\
\hline Immunisation & - & \\
\hline National laboratory system & National laboratory system (9) & $5 / 12(42 \%)$ \\
\hline Real-time surveillance ${ }^{*}$ & Real-time surveillance (18) & $12 / 16(75 \%)$ \\
\hline Reporting & Reporting (3) & $3 / 7(43 \%)$ \\
\hline Workforce development ${ }^{*}$ & Workforce development (19) & $8 / 11(73 \%)$ \\
\hline Preparedness* & Preparedness (15) & $9 / 10(90 \%)$ \\
\hline Emergency response operations* & Emergency response operations (13) & $8 / 9(89 \%)$ \\
\hline Linking public health and security authorities & - & \\
\hline $\begin{array}{l}\text { Medical countermeasures and personnel } \\
\text { deployment }^{*}\end{array}$ & $\begin{array}{l}\text { Medical countermeasures and } \\
\text { personnel deployment (10) }\end{array}$ & $9 / 11(82 \%)$ \\
\hline Risk communication* & Risk communication (14) & $10 / 16(62 \%)$ \\
\hline & Total & $89 / 129(69 \%)$ \\
\hline \multicolumn{3}{|c|}{$\begin{array}{l}\text { Columns report JEE TA (A) which have a component at the animal-human interface (source: OIE-WHO Handbook } 2017^{17} \text { ); (B) for which } \\
\text { recommendations made during the JEE missions can be associated with activities discussed during NBW (in bracket is the number of NBW } \\
\text { activities associated with this TA) and (C) for each TA, proportion of JEE recommendations to which an NBW activity is associated. } \\
{ }^{*} \text { TAs with more than } 70 \% \text { of their recommendations implemented through NBW activities have been marked with an asterisk. } \\
\text { IHR, International Health Regulations; JEE, Joint External Evaluation; NBW, National Bridging Workshops; TA, technical area. }\end{array}$} \\
\hline
\end{tabular}




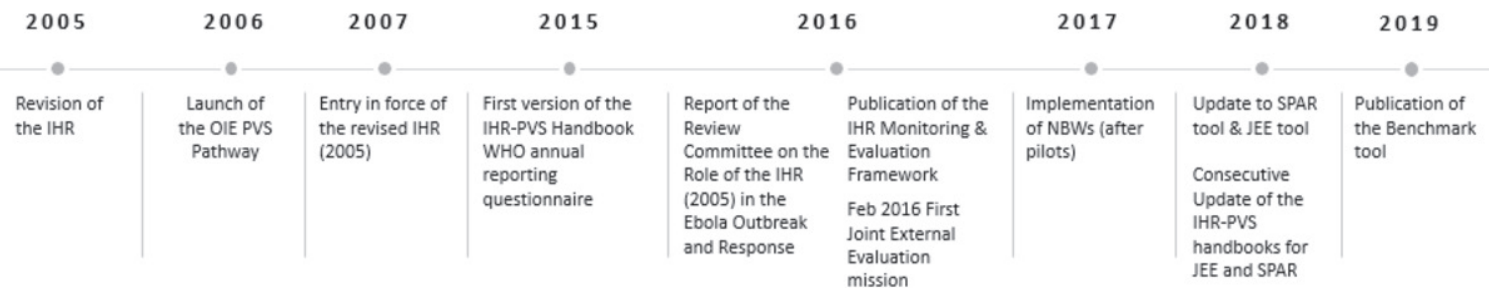

Figure 1 Illustrates the chronology of events that informed the development of tools to support the implementation of IHR.

animal health professionals joining the panel of external experts, was well recognised and contributed to a wider consideration of One Health perspectives in the revision of the JEE tool conducted in $2019 .{ }^{19}$ The chronology of all these events is illustrated in figure 1.

As of November 2020, JEEs have been conducted in a total of 113 countries. During these JEE missions, TAs are discussed using indicators and level of performance scored from 1 (indicating no implementation or very limited implementation) to 5 (performing implementation). As an illustration, the scores for the three indicators of TA zoonotic diseases, all countries included, are summarised in figure 2 and indicate that most countries consider having a surveillance system in place for zoonotic diseases of greatest concern (indicator P 4.1, scores 2-4) and adequate veterinary health forces at national and (most of) subnational levels (indicator $\mathrm{P}$ 4.2, scores 3 and 4). The level of performance of their response mechanism to zoonotic diseases is scored lower (indicator P 4.3, scores 2 and 3), mainly because of limited coordination institutionalised between human, animal and wildlife sectors.

\section{ONE HEALTH ROADMAPS TO OPERATIONALISE THE RECOMMENDATIONS OF JEES}

Beginning in 2014, the effort to use the IHR (2005) as a driving force for the implementation of the One Health approach for health security also resulted in the implementation of IHR-PVS National Bridging Workshops (NBWs) jointly developed by WHO and OIE. ${ }^{20}$ These events conducted in countries provide the opportunity for the two sectors to jointly review the results of the IHR MEF (JEE and/or SPAR) and PVS pathway and to agree on concrete and operational activities to fill the gaps in their coordination between the two sectors for the core functions of the IHR (2005). ${ }^{13}$ The exercise, conducted with professionals from multiple sectors and operating at various level in the national system, used a methodology ensuring full engagement and appropriation of the results by the participants. One of the outputs of a NBW is a jointly developed, detailed, practical, realistic and consensual roadmap prioritising activities to improve coordination at the human-animal-environment interface. Jointly agreed activities included in this roadmap are later used to inform multisectoral One Health action planning. ${ }^{21}$

The need for more interactions between the human health, animal health and environment sectors was widely recognised and almost systematically mentioned in the JEE recommendations (Zinsstag, in press). Given that the NBWs focus on zoonotic diseases and food safety issues, they do not extensively cover four JEE TAs: Antimicrobial resistance, biosafety and biosecurity, immunisation, and linking public health and security authorities. However, biosafety and biosecurity issues are usually addressed in the discussion on laboratories, and despite possible misuse of zoonotic pathogens, no particular priority is being given to the dimension on security.

From the 16 previously mentioned JEE TAs, a total of 180 standardised recommendations were identified, 129 recommendations if the four TAs less extensively covered during the NBWs are removed. In parallel, the database summarising the NBW activities from 22 countries covered from 2017 to 2019 includes 66 standardised activities, grouped in 13 categories. The mapping exercise between the two databases revealed that out of the
Indicator P 4.1 - Surveillance systems in place for priority zoonotic diseases/pathogens

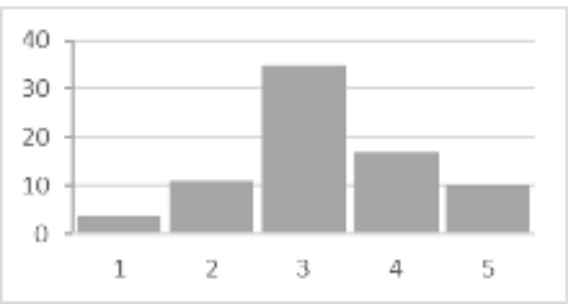

Indicator P 4.2 - Veterinary or Animal Health Workforce

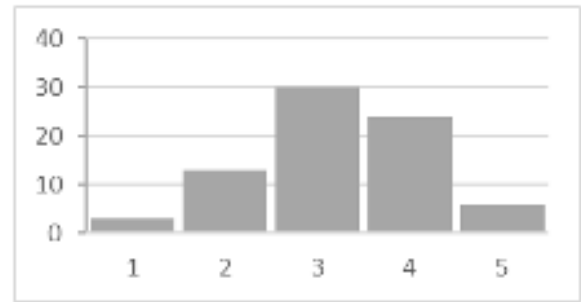

Indicator P 4.3 - Mechanisms for responding to infectious zoonoses and potential zoonoses are established and functional

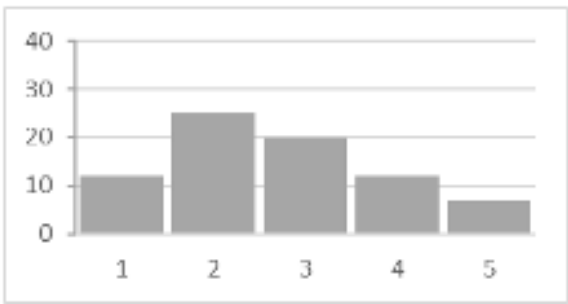

Figure 2 Illustrates the mean scores for three indicators of JEE TA zoonotic diseases, all countries included. 
129 recommendations, $89(69 \%)$ have one or multiple NBW activities associated (table 1 ).

Some TAs (identified with an asterisk in table 1: IHR coordination, communication and advocacy, zoonotic diseases, real-time surveillance, preparedness, emergency response operations, medical countermeasures and personnel deployment) have NBW activities associated with more than $70 \%$ of their recommendations, confirming the contribution of these activities in their operationalisation. Workforce development is also a TA for which concrete activities such as strengthening of curriculum or specific continuing education programmes are frequently proposed during the NBWs. Interestingly, only half of the recommendations made for the food safety TA are associated with NBW activities, possibly because most of its recommendations target a wider scope than the zoonotic component discussed during the NBWs (eg, food safety national plan, guidelines, specific legislation and regulation, control at points of entry and international networks). Most of the JEE recommendations $(64 \%)$ are associated with a unique activity proposed during NBWs; $30 \%$ are associated with two; and $6 \%$ with three or more. The five most informed JEE recommendations, with four NBW activities or more, are reported in table 2, reflecting the needs identified during the NBWs to conduct complementary actions for their implementation.

\section{BENCHMARKING PERFORMANCE AGAINST EXPECTED IHR CORE CAPACITIES}

The WHO Benchmark Tool for IHR capacities (IHR Benchmark Tool, hereby referred to as BT) developed in 2019 proposes a set of actions that can be applied to increase the performance of countries in TAs, thus strengthening their IHR capacities. ${ }^{22}$ The BT covers all 13 IHR capacities delineated in the SPAR and 19 TAs delineated in the JEE tool, slightly differently organised.

Table 2 JEE recommendations for which four or more activities are included in the NBW roadmaps

JEE recommendation NBW activity

Structure and Establish a multisectoral technical committee.

formalise a

framework for the coordination of IHR.

Nominate focal points with Terms of Reference for multisectoral coordination at local levels.

Develop Memorandum of Understanding for multisectoral coordination.

Regular meeting of focal points.

Subnational One Health platforms/working groups.

Improve workforce capacities for the management of Zoonotic Diseases.

Update school/student curricula with information on zoonoses and One Health approach.

Develop a One Health epidemiology training programme/joint master course/postgraduate programmes.

Field Epidemiology Training Programme

Recruit.

Organise the surveillance and risk assessment of food events.

Develop/harmonise joint surveillance strategy on priority zoonoses.

Conduct Joint Risk Assessment.

One Health surveillance team/group/focal points for joint surveillance

Set up a Joint Risk Assessment group/committee.

Improve human and Equip/modernise laboratories for routine diagnostics of zoonosis.

technical laboratory capacities.

Training for laboratory personnel on routine diagnosis of zoonosis.

Lab needs assessment.

Mapping labs/lab personnel.

Improve capacity for and conduct risk assessments

Adopt/develop Joint Risk Assessment tool/guidelines.

Joint training on Joint Risk Assessment

Conduct Joint Risk Assessment.

Set up a Joint Risk Assessment group/committee.

Identify and address training needs specific to professions.

Training for focal points at local level (on Standard Operating Procedures).

Training for laboratory personnel on routine diagnosis of zoonosis.

Conduct training on joint risk communication.

Training (general)

Develop a One Health epidemiology training programme/joint master course/postgraduate programmes.

Joint training on surveillance

Training on joint investigation and response

IHR, International Health Regulations; JEE, Joint External Evaluation; NBW, National Bridging Workshops. 
Table 3 Benchmarks and associated NBW activities

\begin{tabular}{|c|c|c|c|}
\hline Benchmark TAs & Benchmarks & A & B \\
\hline \multirow[t]{3}{*}{$\begin{array}{l}\text { National legislation, } \\
\text { policy and financing }\end{array}$} & $\begin{array}{l}\text { Domestic legislation, laws, regulations, policy and administrative requirements are } \\
\text { available in all relevant sectors and effectively enable compliance with the IHR. }\end{array}$ & 1 & \multirow[t]{3}{*}{4} \\
\hline & Financing is available for the implementation of IHR capacities. & 2 & \\
\hline & Financing is available for timely response to public health emergencies. & 1 & \\
\hline \multirow{2}{*}{$\begin{array}{l}\text { IHR coordination, } \\
\text { communication } \\
\text { and advocacy and } \\
\text { reporting }\end{array}$} & The IHR National Focal Point is fully functional. & 4 & \multirow[t]{2}{*}{9} \\
\hline & $\begin{array}{l}\text { Multisectoral IHR coordination mechanism effectively supports the implementation of } \\
\text { prevention, detection and response activities }\end{array}$ & 7 & \\
\hline \multirow[t]{2}{*}{ Zoonotic diseases } & Coordinated surveillance system is in place for priority zoonotic diseases/pathogens. & 30 & \multirow[t]{2}{*}{43} \\
\hline & Functional mechanism to respond to priority zoonotic diseases is in place. & 23 & \\
\hline \multirow[t]{2}{*}{ Food safety } & $\begin{array}{l}\text { Surveillance systems are in place for the detection and monitoring of foodborne } \\
\text { diseases and food contamination. }\end{array}$ & 21 & \multirow[t]{2}{*}{30} \\
\hline & $\begin{array}{l}\text { A functional mechanism is in place for the response and management of food safety } \\
\text { emergencies. }\end{array}$ & 15 & \\
\hline \multirow{4}{*}{$\begin{array}{l}\text { National laboratory } \\
\text { system }\end{array}$} & Laboratory testing for detection of priority diseases is in place. & 11 & \multirow[t]{4}{*}{12} \\
\hline & Specimen referral and transport system are in place for all relevant sectors. & 3 & \\
\hline & Effective national diagnostic network is in place. & 9 & \\
\hline & Laboratory quality system is in place. & 1 & \\
\hline \multirow[t]{3}{*}{ Surveillance } & $\begin{array}{l}\text { Functional surveillance system to identify potential events of concern for public health } \\
\text { and health security is in place. }\end{array}$ & 11 & \multirow[t]{3}{*}{16} \\
\hline & Surveillance system is supported by electronic tools. & 4 & \\
\hline & Systematic analysis of surveillance data for action is in place. & 4 & \\
\hline \multirow[t]{4}{*}{ Human resources } & An up-to-date, multisectoral workforce strategy is in place. & 7 & \multirow[t]{4}{*}{18} \\
\hline & Human resources are available to effectively implement IHR. & 12 & \\
\hline & In-service trainings are available. & 9 & \\
\hline & $\begin{array}{l}\text { Field epidemiology training programme or other applied epidemiology training } \\
\text { programme is in place. }\end{array}$ & 2 & \\
\hline \multirow[t]{2}{*}{$\begin{array}{l}\text { Emergency } \\
\text { preparedness }\end{array}$} & $\begin{array}{l}\text { Strategic emergency risk assessments are conducted, and emergency resources are } \\
\text { identified, mapped and used. }\end{array}$ & 11 & \multirow[t]{2}{*}{16} \\
\hline & Multisectoral planning for health emergency preparedness and response is in place. & 9 & \\
\hline \multirow{3}{*}{$\begin{array}{l}\text { Emergency } \\
\text { response operations }\end{array}$} & Functional emergency response coordination is in place. & 9 & \multirow[t]{3}{*}{13} \\
\hline & Emergency operation centre capacities, procedures and plans are in place. & 7 & \\
\hline & Emergency exercise management programme is in place. & 2 & \\
\hline $\begin{array}{l}\text { Linking public } \\
\text { health and security } \\
\text { authorities }\end{array}$ & $\begin{array}{l}\text { Public health and security authorities (law enforcement, border control and customs) } \\
\text { are linked during a suspect or confirmed biological, chemical or radiological event. }\end{array}$ & 6 & 6 \\
\hline \multirow{3}{*}{$\begin{array}{l}\text { Medical } \\
\text { countermeasures } \\
\text { and personnel } \\
\text { deployment }\end{array}$} & $\begin{array}{l}\text { System is in place for activating and coordinating medical countermeasures during a } \\
\text { public health emergency. }\end{array}$ & 2 & \multirow[t]{3}{*}{2} \\
\hline & $\begin{array}{l}\text { System is in place for activating and coordinating health personnel during a public } \\
\text { health emergency. }\end{array}$ & 0 & \\
\hline & Case management procedures implemented for relevant IHR hazards. & 0 & \\
\hline \multirow{3}{*}{ Risk communication } & Risk communication systems for unusual events and emergencies are in place. & 7 & \multirow[t]{3}{*}{10} \\
\hline & Coordination of risk communication is effective. & 4 & \\
\hline & Effective communication with communities & 4 & \\
\hline
\end{tabular}

Column (a) reflects the number of NBW activities per benchmark, and column (b) reflects the number of different NBW activities per Benchmark TA.

IHR, International Health Regulations; NBW, National Bridging Workshops; TA, technical area. 
For example, the JEE has three indicators for zoonotic diseases but this TA is covered by only two benchmarks, the actions related to veterinary workforce being included in the benchmark on human resources instead.

Similar to the JEE, NBW activities can be associated with 12 BT TAs, in which 30 out of 32 benchmark actions are further informed and operationalised by a total of 58 different NBW activities (table 3). Benchmarks on zoonosis and food safety logically gather the highest number of associations and the widest diversity of NBW activities (respectively $74 \%$ and $52 \%$ of the NBW activities listed are associated with these TAs). In comparison, a large number of NBW activities can be associated with human resources, but with a lower diversity (31\%), meaning that most of the NBW activities associated with its four benchmarks are the same.

Interestingly, NBW activities are often associated with improvement at a low level of performance in the BT. A global review indicates that $36 \%$ of NBW activities are associated with an improvement from level 1 to level 2, and 35\% from level 2 to level 3, all TAs considered together. In more details for the TA on zoonotic diseases, $19 \%$ of NBW activities support the improvement from level (L) 1 to L2 of benchmark 4.1 (Coordinated surveillance system for priority zoonotic diseases) and $47 \%$ from L2 to L3. For benchmark 4.2 (Mechanism to respond to priority diseases), $19 \%$ of NBW activities support progress from L1 to L2, and 54\% from L2 to L3. Similarly, for the TA on human resources, which includes the veterinary workforce, frequencies are $40 \%$ from L1 to L2, and $40 \%$ from L2 to L3. These results contrast with those of the JEE, when performances were ranked higher, for surveillance and workforce development (figure 2), revealing that countries often overestimate their capacities at the human-animal-environment interface during JEE. Deeper, more focused and nuanced discussions between professionals during NBWs highlight the need to strengthen foundations of multisectoral coordination for most of the TAs.

\section{CONCLUSION}

Operationalising One Health, multisectoral approaches remain challenging, even when the need for collaboration seems obvious as it is the case at the human-animalenvironment interface for the management of zoonotic diseases. A number of institutional and administrative problems hamper collaboration across various ministries. ${ }^{8}$ There may simply be legal or other structural and functional barriers to cooperation between sectors like public health, animal health, wildlife, environment and other relevant partners, such as diverging mandates or rivalries over budget allocations. There may also be cultural and perception issues to overcome, requiring cultural shifts and behavioural changes among professionals within agencies. ${ }^{12}$ Joint review of capacities and resulting evaluation frameworks is an effective and efficient exercise to improve dialogue. This allows for the shared exploration of synergies between sectors, allowing them to act jointly, using One Heath tools developed for strengthening specific or more transversal TAs. ${ }^{23}$ Deeper follow-up discussions and the engagement of a wider professional audience and relevant authorities, including those working at the subnational levels in countries, help to complement the recommendations with more concrete and operational inputs. In particular, detailed planning of activities jointly developed for critical TAs such as surveillance, human resources and workforce development, field investigation, laboratory functions and joint response to emergencies is instrumental in building partnerships and coordination between sectors, which strengthen almost all the IHR core capacities reviewed in the IHR MEF. Even more productive is to build on this coordination with concrete activities such as joint risk assessments, after-action reviews or simulation exercises, which create the opportunity to test the reported performance. ${ }^{524}$

There is currently a concerted effort to ensure that IHR core capacities are an integral part of broader health systems to achieve both goals of health security and universal health coverage. ${ }^{25}$ This approach and associated principles are fully endorsed by the international community as a way forward to help countries build back better after COVID-19, and were already reinforced years ago by the tripartite-FAO, OIE and $\mathrm{WHO}$ - in their first tripartite concept note. ${ }^{26}$ It can be expected that the implementation of the NBW roadmaps can contribute to this integrative effort for a more coordinated approach, ultimately strengthening collaborative capacity at the human-animal-environment interface.

\section{Author affiliations \\ ${ }^{1}$ Health Emergencies Programme, WHO, Geneva, Switzerland \\ ${ }^{2}$ Veterinary Population Medicine, University of Minnesota, St. Paul, Minnesota, USA ${ }^{3}$ Country Health Emergency Preparedness \& IHR, WHO Regional Office for Europe, Copenhagen, Denmark \\ ${ }^{4}$ Emergency Preparedness, WHO Regional Office for Africa, Brazzaville, Congo ${ }^{5}$ Healthier Populations \& Noncommunicable Diseases, WHO Regional Office for South-East Asia, New Delhi, India \\ ${ }^{6}$ Country Health Emergency Preparedness \& IHR, WHO Regional Office for the Eastern Mediterranean, Cairo, Egypt \\ ${ }^{7}$ Capacity Building Department, World Organisation for Animal Health, Paris, France}

Contributors This article has been informed by the authors' research, practice and evaluation of the use of Joint External Evaluation (JEE), WHO Benchmark Tool and National Bridging Workshops (NBWs) to support improved coordination between human health and animal health sectors in countries. SdIR, GB, AS, TS, TT, NI, GG, FC and MC supported the development and piloting of the NBW methodology, including a cross analysis of International Health Regulations (IHR) and Performance of Veterinary Services. SdIR, GB, KMME, RS, DS, AT, NK, JX and SC contributed their expertise in IHR and JEE, as well as related tools and approaches for strengthening collaborative health security. All authors were involved in developing, writing and revising the article.

Funding The authors have not declared a specific grant for this research from any funding agency in the public, commercial or not-for-profit sectors.

Competing interests None declared.

Patient and public involvement Patients and/or the public were not involved in the design, conduct, reporting or dissemination plans of this research.

Patient consent for publication Not required. 
Provenance and peer review Not commissioned; externally peer reviewed.

Data availability statement Data are available in a public, open access repository.

Open access This is an open access article distributed under the terms of the Creative Commons Attribution IGO License (CC BY NC 3.0 IGO), which permits use, distribution, and reproduction in any medium, provided the original work is properly cited. In any reproduction of this article there should not be any suggestion that WHO or this article endorse any specific organization or products. The use of the WHO logo is not permitted. This notice should be preserved along with the article's original URL.

Disclaimer: The author is a staff member of the World Health Organization. The author alone is responsible for the views expressed in this publication and they do not necessarily represent the views, decisions or policies of the World Health Organization.

ORCID iD

Ambrose Talisuna http://orcid.org/0000-0001-6436-3415

\section{REFERENCES}

1 Daszak P, Olival KJ, Li H. A strategy to prevent future epidemics similar to the 2019-nCoV outbreak. Biosaf Health 2020;2:6-8.

2 Bengis RG, Leighton FA, Fischer JR, et al. The role of wildlife in emerging and re-emerging zoonoses. Rev Sci Tech 2004:23:497-511.

3 Morens DM, Fauci AS. Emerging infectious diseases: threats to human health and global stability. PLoS Pathog 2013;9:e1003467.

4 Gibbs EPJ. The evolution of one health: a decade of progress and challenges for the future. Vet Rec 2014;174:85-91.

5 FAO, OIE, WHO. Taking a multisectoral, one health approach: a tripartite guide to adressing zoonotic diseases in countrie, 2019. Available: https://extranet.who.int/sph/sites/default/files/documentlibrary/document/Tripartite-Guidance-EN-web\%20single\%20page. pdf

6 Zinsstag J, Schelling E, Wyss K, et al. Potential of cooperation between human and animal health to strengthen health systems. Lancet 2005;366:2142-5.

7 Spencer J, McRobie E, Dar O, et al. Is the current surge in political and financial attention to one health solidifying or splintering the movement? BMJ Glob Health 2019;4:e001102.

8 Okello AL, Bardosh K, Smith J, et al. One health: past successes and future challenges in three African contexts. PLoS Negl Trop Dis 2014;8:e2884.

9 Errecaborde KM, Macy KW, Pekol A, et al. Factors that enable effective One Health collaborations - A scoping review of the literature. PLoS One 2019;14:e0224660.

10 World Health Organization. International health regulations (2005). 3rd edn. Geneva: WHO, 2016: 74. http://www.who.int/ihr/ publications/9789241580496/en/
11 De La Rocque S, Caya F, El Idrissi AH, et al. One health operations: a critical component in the International health regulations monitoring and evaluation framework. Rev Sci Tech 2019;38:303-14.

12 Nuttall I, Miyagishima K, Roth C, et al. The United nations and one health: the International health regulations (2005) and global health security. Rev Sci Tech 2014;33:659-68.

13 De La Rocque S, Tagliaro E, Belot G, et al. Strengthening good governance: exploiting synergies between the performance of veterinary services pathway and the International health regulations (2005). Rev Sci Tech 2017;36:711-20.

14 OIE. The OIE PVS pathway. Paris: OIE, 2018. www.oie.int/en/ support-to-oie-members/pvs-pathway/

15 WHO. International health regulations (2005) IHR monitoring and evaluation framework. Geneva: WHO, 2018: 20.

16 WHO. The joint external evaluation: international health regulations 2005). Geneva: WHO, 2016: 92. www.who.int/ihr/publications/WHO_ HSE_GCR_2016_2/en/

17 WHO, OIE. Handbook for the assessment of capacities at the human-animal interface. second edition related to the joint external evaluation tool international health regulations (2005. Geneva: WHO, 2017: 50. http://www.who.int/ihr/publications/9789241511889/en/

18 Kandel N, Sreedharan R, Chungong S, et al. Joint external evaluation process: bringing multiple sectors together for global health security. Lancet Glob Health 2017;5:e857-8.

19 McPhee E, Gronvall GK, Sell TK. Analysis of sectoral participation in the development of joint external evaluations. BMC Public Health 2019;19:631.

20 Belot G, Caya F, Errecaborde KM, et al. IHR-PVS national bridging workshops, a tool to operationalize the collaboration between human and animal health while advancing sector-specific goals in countries. Plos One 2021.

21 Gongal G, Ofrin RH, de Balogh K, et al. Operationalization of one health and tripartite collaboration in the Asia-Pacific region. WHO South East Asia J Public Health 2020;9:21-5.

22 WHO. Benchmarks for international health regulations (IHR) capacities. Geneva: WHO, 2019: 140.

23 Pelican K, Salyer SJ, Barton Behravesh C, et al. Synergising tools for capacity assessment and one health operationalisation. Rev Sci Tech 2019;38:71-89.

24 Copper FA, Mayigane LN, Pei Y, et al. Simulation exercises and after action reviews - analysis of outputs during 2016-2019 to strengthen global health emergency preparedness and response. Global Health 2020;16:115.

25 Kluge H, Martín-Moreno JM, Emiroglu N, et al. Strengthening global health security by embedding the International health regulations requirements into National health systems. BMJ Glob Health 2018:3:e000656

26 FAO, OIE, WHO. Sharing responsibilities and coordinating global activities to address health risks at the animal-human-ecosystems interfaces. A tripartite concept note, 2010. Available: www.oie.int/ fileadmin/Home/eng/Current_Scientific_Issues/docs/pdf/FINAL CONCEPT NOTE Hanoi.pdf 